\title{
Announcing a New Psychonomic Society Journal Psychonomic Bulletin \& Review
}

The Publications Committee of the Psychonomic Society has authorized the publication of a new journal: Psychonomic Bulletin \& Review. The new journal, a quarterly, with the first issue to appear in March 1994, will be a fully refereed journal, and its first editor will be Henry L. Roediger III of Rice University.

The journal will cover topics that form the basis of traditional experimental psychology, including

- animal learning and behavior

- judgment and decision-making

- memory and cognition

- psychobiology and cognitive neuropsychology

- psychophysics and perception

- social cognition and cognitive development

The aim is to publish broadly conceived papers of interest to experimental psychologists.

Papers in the following four categories will be considered: (1) review papers that summarize and synthesize a well-defined body of work; (2) theoretical papers that announce a new theory or provide a novel interpretation of a previously accepted theory; and (3) articles that may not state a new theory or review a body of literature but instead comment on trends in the field. These three types of articles-review, theory, and opinion-may be of any length. In general, such articles will not report new experimental data, although brief descriptions of new findings may be included to buttress a theoretical point.

In addition, Psychonomic Bulletin \& Review will also publish (4) brief reports which may include new experimental data. The same length restrictions for brief reports that were followed for publication in the Bulletin of the Psychonomic Society will be implemented, with papers not to exceed 4 journal pages. Longer manuscripts reporting experimental data should be submitted to one of the other appropriate journals published by the Psychonomic Society. Brief inquiries concerning the possible appropriateness of submissions may be made to the editor at the address below or by electronic mail (prj@ricevm1.rice.edu).

Manuscripts should be sent to: Henry L. Roediger III, Department of Psychology, Rice University, P.O. Box 1892, Houston, TX 77251-1892. They should be submitted in quintuplicate and should adhere to the conventions concerning abstracts, format, references, etc., described in the Publication Manual of the American Psychological Association (3rd ed.). With the final accepted version of the manuscript, a copy of that version should be submitted on a computer disk in ASCII (text only) format. 